http://jmscr.igmpublication.org/home/ ISSN (e)-2347-176x ISSN (p) 2455-0450 crossref DOI: https://dx.doi.org/10.18535/jmscr/v8i7.59

\author{
Journal Of Medical Science And Clinical Research \\ IGM Publication \\ An Official Publication of IGM Publication
}

\title{
A Review of Corona Virus Disease-2019
}

Authors

\section{A.Mishal*, R.Saravanan, S.Sakthi Atchitha, K.Santhiya, M.Rithika, S.Sanju Menaka, T.Thiruvalluvan}

Department of Pharmacy Practice, Jaya College of Paramedical Sciences, College of Pharmacy, Thiruninravur,

Chennai-602024, INDIA

*Corresponding Author

\section{A.Mishal}

\begin{abstract}
Epidemic often occurs with zoonotic origin, viruses such as Ebola, Zika and SARS outbreak serves as an example. A zoonotic virus which belongs to Coronaviridae family emerged in Wuhan, China spreads around the world through human-human transmission by having ACE II receptor as binding site and was named as SARS CoV-2.Clinically they are diagnosed with a confirmatory molecular test, blood test, CT scan to the people who has symptoms of breathlessness, fever (for more than one week), cough, sore throat, headache, anosmia, ageusia and in asymptomatic condition person's travelling history to infected countries or having close contact with infected patient helps in diagnosis. Till now there is no officially recognised treatment for COVID-19 which was managed by symptomatic relief and by some antiviral drug so, prevention plays an important role to supress the spread. Several preventive measures have been implemented by the health care workers and the government to reduce the spread of COVID-19 such as social distancing, self-quarantining, use of mask, personal hygiene and use of hand sanitizer were followed at community level

Keywords: Zoonotic virus, SARS CoV-2, COVID-19, ACE II receptor.
\end{abstract}

\section{Introduction}

At the end of 2019, emerged a disease which was latterly found to be a viral infection originated in China and spreads all over the world through human-human transmission. They cause milder to severe infection depending upon the host immune response and was one among the zoonotic viruses. More than $70 \%$ similarity with SARS CoV the virus was named as SARS Cov-2 by International Committee on Taxonomy of viruses and the disease as COVID-19 (Corona Virus Disease 2019) by WHO Director General Dr.Tedross Adhanom Ghebreyesus. Till now, there is no officially recognized treatment but are managed by symptomatic relief and by some antiviral drugs. Production of vaccines against COVID-19 is one of the most important goal for many countries to eradicate the virus. This article gives keen view about COVID-19 updated till 04/07/2020.

\section{History}

Corona virus have extensive range of natural host due to its positive sense of RNA ranging from $60 \mathrm{~nm}$ to $140 \mathrm{~nm}$ in diameter belongs to the Coronaviridae family in the nidovirales order. 
There are 4 subgroups of CoV's family namely alpha $(\alpha)$, beta $(\beta)$, gamma $(\gamma)$ and delta $(\delta)$. Earlier it was believed that they only infect animals until the outbreak of SAR-CoV (Severe Acute Respiratory Syndrome Corona Virus) a beta subgroup in 2002 at Guangdong, China. Bats were their origin and palm civet are the intermediary host, affects 8098 humans in 26 countries at 9\% fatality rate causing acute lung injury (ALI) and acute respiratory distress syndrome (ARDS). Middle east respiratory syndrome corona virus (MERS) with similar complication as in SARSCoV provokes after a decade affects 2428 humans out of which 838 were dead. Emerged in Saudi Arabia with dromedary camels as intermediate host. In 2019 SARS Cov-2 originated from Bat and the intermediary animal was still unknown causing fever, cough, ARDS, shortness of breath, anosmia in human.

\section{Origin and Spread}

Five patients were hospitalized with ARDS believed to have pneumonia on $18^{\text {th }}$ to $29^{\text {th }}$ December 2019. One of the patients was died in hospital, several other cases were reported with the same symptoms and has a common exposure to Huanan whole sale sea food market that also traded live animals. On $31^{\text {st }}$ December 2019 Wuhan municipal health commission, China reported many cases of pneumonia in Wuhan. Due to this spread, respiratory samples of patient were collected for etiological investigations by the activated surveillance system. The Hunan wet market was closed on $1^{\text {st }}$ January 2020. Through unknown mechanism 41 patients had the same infection from the patients who was hospitalized between $18^{\text {th }}$ to $29^{\text {th }}$ December 2019. The spread of the pneumonia in Wuhan, Hubei province was reported by WHO through social media on $4^{\text {th }}$ January 2020 and on $5^{\text {th }}$ January 2020 WHO published $1^{\text {st }}$ disease outbreak news on the new virus. On $7^{\text {th }}$ January the virus had $>95 \%$ homology with bat coronavirus and $>70 \%$ with SARS CoV and was identified as Corona virus. By $12^{\text {th }}$ January 2020 , the genetic sequence of
COVID-19 was publicly shared by China. The next day, the first case outside china of COVID19 was officially confirmed in 61 years old Chinese women who travelled from Wuhan city with 5 family members in a tour group of 16 people to Thailand. The 61 years old women didn't have the history of visiting Huanan sea food market, where the most cases were detected. By $22^{\text {nd }}$ January the COVID-19 affected cases were increased to 563. Human to human transmission was confirmed by the infected people with COVID-19 in many countries who had no history of traveling to China. Wuhan which had 11 million populations was placed under lockdown on $23^{\text {rd }}$ January 2020, soon many cities of Hubei province were in lock down. China had 14,380 cases on $1^{\text {st }}$ February 2020, 79,824 cases on $29^{\text {th }}$ February 2020 and 83,545 on $4^{\text {th }}$ July 2020. Screening mechanism was initiated in all country airports to test COVID-19 infection who are returning from China. Since COVID-19 can spread through a patient before the onset of symptom all the travellers returning from china symptomatic or asymptomatic were isolated for 14 days and tested them for virus. By testing the travellers from china many countries had the first case of COVID-19 such as India had the first confirmed case on $30^{\text {th }}$ January 2020 by screening a student who travelled from Wuhan to India on $23^{\text {rd }}$ January 2020 night. India had 7,599 cases on $10^{\text {th }}$ April 2020 and 673,904 cases on July $4^{\text {th }}$ 2020. Italy had the first case on $31^{\text {st }}$ January 2020 in a Chinese couple who travelled from Wuhan, by the mid of February 2020 further 3 cases were reported with the travelled history from China or having contact with the people who travelled from China and had 47,041 cases on $20^{\text {th }}$ march 2020, 1,87,290 cases on $22^{\text {nd }}$ April 2020, 241,419 cases on 4th July 2020. United states of America had their first case on $19^{\text {th }}$ January 2020 who visited his family in Wuhan and returned to Washington on $15^{\text {th }}$ January 2020.

Top 5 countries on 04/07/2020 which had wide spread of COVID-19

USA-2,935,770 
Brazil-1,578,376

Russia-674,515

India-673,904

Peru-299,080

\section{Epidemiology}

First four cases of Acute Respiratory Syndrome were identified in Wuhan city, China on $31^{\text {st }}$ December 2019. As of $4^{\text {th }}$ July 2020, in worldwide there are 11,372,202 confirmed cases, 6,433,931 were recovered and 532,864 death.

In India there are 673,904 confirmed cases, 409,062 were recovered and 19,279 death till July $4^{\text {th }} 2020$

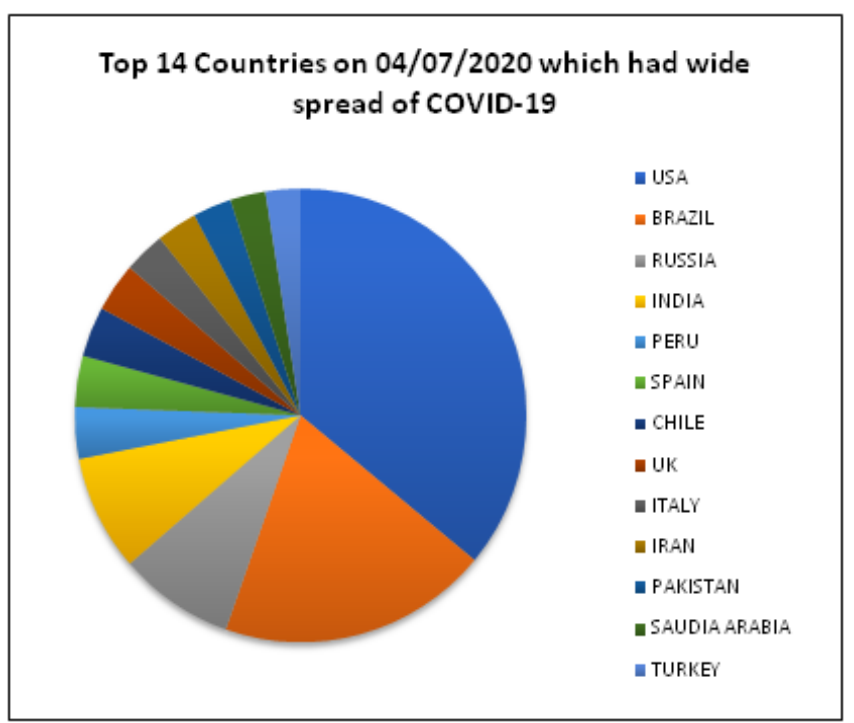

\section{Pathogenesis}

Having 1 to 14 days of incubation period SARS CoV-2 gain access to the alveolar epithelial cell inside the lung through fomites results in respiratory symptoms. Since ACE-II are the binding receptor of SARS $\mathrm{CoV}$, SARS CoV-2 also have the same binding site with spike as surface protein. Once they gain access to cytoplasm by encoding the host membrane through endocytosis or direct fusion, they are uncoated and the positive stranded RNA genome (+) ss RNA attaches to the host ribosomes which produces RNA polymerase lead to the production of negative RNA strand (-) ss RNA. RNA polymerase produces positive RNA strand and other positive small RNA strands with the help of negative RNA strand. These small RNA strands are packed with Golgi apparatus then starts producing new viruses along with positive RNA strand which are then released from host cell by exocytosis through secretory vesicles.

They not only replicate inside alveoli but also damages it which provokes the release of interferon, cytokines and intracellular components. To increase antiviral defence interferon signals the nearly cells. Alveolar macrophytes detect cell injury, which secrete cytokines TNF $\alpha$, IL 1, IL 6 , IL 8 and chemokines. Inflammatory persist occurring with the lung pair stimulates nerve ending to initiate cough reflux. TNF $\alpha$, IL 1 cause increase in vascular permeability, allows neutrophils and monocytes to bind and enter the site of injury. IL 8 overcoat the neutrophils and other chemokines attack the monocytes. Increased vascular permeability causes leakage of fluid causes interstitial oedema. Inside the alveoli cause pulmonary oedema, which cause dyspnoea, hypoxaemia. Neutrophils engulf the virus which release the toxic by-products by damaging the tissues and alveolar cells all over. Less surfactant made the alveoli to collapse results in hypoxaemia. White blood cells damage the alveolar cells which release $\mathrm{t}$ leukotriene's, prostaglandins. Prostaglandins, TNF $\alpha$, IL 1, IL 6 causes fever. Asymptomatic patient will have minor symptoms like cough, fever, etc. Alveolar macrophage engulf virus through phagocytosis and attached to the spike protein of virus that are recognized by specific immune cell which produce antibody against spike viral proteins. IL 6 stimulates phagocytes to produce acute phage reactant including CRP (produce inflammation), fibrinogen and hepcidin, lung injury along with hypoxaemia to various organ cause acute respiratory distress syndrome (ARDS) which are the severe cause of mortality in COVID-19. The recovery time for mild infection is 2 weeks and for severe, it is $3-6$ weeks. 


\section{Clinical Feature}

Mild, moderate or severe symptoms were observed in COVID-19 infection. In mild cases, variety of atypical symptoms such as fever, cough, headaches, sore throat, nausea/vomiting, fatigue, delirium and chest pain that may occur over an extended period. Pneumonia may progress in first week due to the inflammatory cytokines, including IPIO, MCTI, MITIA, TNF $\alpha$, IL2, IL7, IL10. In severe cases, fever which are prolonged or intermittent, cough often dry, non-productive, anosmia and shortness of breath needs medical care for symptomatic relief. Age is a strong risk factor, people who are above age 65 having serious underlying illness like diabetes, cardiovascular diseases, respiratory diseases, HIV infection can have serious complication with COVID-19 such as pneumonia, acute respiratory distress syndrome (ARDS), cardiac injury, arrythmia, septic shock, liver dysfunction, acute kidney injury and multiorgan failure. Children are asymptomatic or have mild infection with COVID-19. Most of them have symptoms of cough, fever and recovered with symptomatic therapy.

\section{Diagnosis of COVID-19}

The diagnostic test for SARS CoV-2 which causes COVID-19 is conducted based on the individuals who have close contact with COVID-19 confirmed cases or the people who travelled and suspected exposure to the area which serve COVID-19 as hotspots, however because of epidemic spread the travel history can be irrelevant. The people who also have fever, cough, shortness of breath or difficulty in breathing, fatigue, sore throat, diarrhoea, headache, loss of taste or smell, inability to walk or stay awake were also suspected to have COVID-19. Detection of virus in stool and in blood can lead to the laboratory test such as molecular test, FBC (Full Blood Count), ESR (Erythrocyte sedimentation rate), IL-6 (Interleukin 6), LDH (Lactate Dehydrogenase Test), Inflammatory markers (Creactive protein) usually an elevated CRP and
ESR are diagnosed. A confirmed case is a suspect with a positive molecular test such as RT-PCR test which detect viral RNA of COVID-19 in nasopharyngeal swab, oropharyngeal test, anterior nasal swab and mid-turbinate - collected from upper respiratory tract. The patient with severe respiratory illness is diagnosed as COVID-19 with the increased size, number, density of ground glass opacities in the chest Computed Tomography scan (CT scan).

\section{Treatment}

Prevention is always better than cure since there is no officially recognised treatment for COVID-19, management and prevention plays major role. In milder infection of SARS-CoV -2, they can be managed by symptomatic relief and boosting the host immune system by foods such as citrus rich fruits, broccoli, almonds, spinach and papaya. Further they are quarantined at home to avoid further spread and counselled about severe symptoms which are to be informed to health professionals for further treatment. Supportive treatments can be established in conditions such as Acute Respiratory Distress Syndrome (ARDS) to manage hypoxia - oxygen can be provided through high flow nasal cannula (HFNC) or noninvasive ventilation (face mask, nasal prongs), in septic shock hemodynamic support can be established isotonic crystalloids within $3 \mathrm{hrs}$ through I.V. Since ACE II is a functional receptor of SARS CoV-2 umisenovir (Arbidol) which inhibit the membrane fusion, 200mg can be administrated orally (not in US). Immunomodulatory effect of chloroquine phosphate (500mg BD for 5 to 10 days) and hydroxychloroquine sulphate (Dose $400 \mathrm{mg}$ BD for 1 day followed by 200mg BD for 4 days) can be used because of its inhibitory action of cytokine production, auto phagy and lysosomal activity in host cells. viral RNA polymerase inhibitors such as favipiravir (1800mg BD - for 1day followed by $800 \mathrm{mg}$ BD up to 14 days) and remdesivir (200mg IV OD - for 1day followed by $100 \mathrm{mg}$ IV OD for 2 to 10 days) can be used. Since 
the virus suppresses the immune system secondary bacterial infection can occur and they are managed by administrating broad spectrum antibiotics such as Azithromycin (500mg OD for 5 days), more evidence is needed before the drugs were recommended. Antibiotics and antivirals should be avoided in routine usage.

New vaccine was developed in India for COVID19 by Bharath biotech international Ltd. In collaboration with ICMR - National institute of virology, Pune. DCGI Approval for phase I and phase II human trials was received for vaccine in India.

\section{Prevention}

COVID-19 infection had no approved treatment till now (05-07-2020) and have been managed by symptomatic treatment or by providing antiviral drugs. Here, prevention plays a major role to control the spread. "Prevention is better than cure", is an old saying related to health based on the fact several preventive measures have been implemented by the healthcare workers and governments to reduce the spread of COVID-19.

Home quarantining is recommended for the people who confirmed or suspected with mild illness. They must be educated with signs and symptoms of serious illness. To avoid the spread of infection to their family members or caregivers the place where they quarantined must be well ventilated and have natural lightening for the destruction of virus. Care takers or family members should wear surgical mask or N95 mask and hand sanitizers or wash hands for every 15minutes. Disinfect the quarantined place frequently as virus can survive on surfaces for serval hours.

At community level, Practice personal hygiene such as regular hand washing with soap and water or using an alcohol-based sanitizer for at least 20 seconds. Cover the nose and mouth with tissues while coughing and sneezing, discard the tissues safely and wash hands immediately. Avoid touching the face nose and mouth after unexpected contact with the virus contaminated surfaces. Always wear clean reusable mask while shopping in the supermarket, other public places and maintain at least 6 feet distance between others. Avoid unnecessary social gatherings. Advise to take plenty of nutritious food and avoid intake of unwashed fruits, vegetables and raw meat products. Mandatory screening for individuals who had a travel history of COVID-19 Hotspots, and who had close contact with the COVID-19 diagnosed patients.

At healthcare workers $21 \%$ were affected during SARS outbreak so it is mandatory to protect healthcare worker from COVID-19. Several preventive measures such as gown, gloves, head cover, mask, respirator, eye protection and shoe cover were used in COVID-19 outbreak which serves barrier and prevent contact from pathogens.

\section{Conclusion}

Most of the people encounter this type of viruses at least once in a life time. This review helps to understand COVID-19 their origin, mode of transmission, clinical symptoms, diagnosis as well as supportive treatment and preventive measures.

\section{Reference}

1. Holmes, K. V. et al. Coronavirus receptor specificity. Adv. Exp. Med. Biol. 342, 261-266 (1993).

2. Rota, P. A. et al. Characterization of a novel coronavirus associated with severe acute respiratory syndrome. Science 300, 1394-1399 (2003).

3. Bonavia, A., Zelus, B. D., Wentworth, D. E., Talbot, P. J. \& Holmes, K. V. Identification of areceptor-binding domain of the spike glycoprotein of human coronavirus HCoV-229E. J. Virol. 77,2530-2538 (2003).

4. Crackower, M. A. et al. Angiotensinconverting enzyme 2 is an essential regulator of heart function. Nature 417, 822-828 (2002).

5. Leung, W. K. et al. Enteric involvement of severe acute respiratory syndrome- 
associated coronavirus infection.

Gastroenterology 125, 1011-1017 (2003).

6. Rahman A, Sarkar A. Risk factors for fatal middle east respiratory syndrome coronavirus infections in Saudi Arabia: analysis of the WHO Line List, 20132018. Am J Public Health 2019;109 (9):1288-93.

7. Phan LT, Nguyen TV, Luong QC, Nguyen TV, Nguyen HT, Le HQ, et al.Importation and human-to-human transmission of a novel coronavirus in Vietnam. $\mathrm{N}$ Engl $\mathrm{J}$ Med 2020.

8. Paden C, Yusof M, Al Hammadi Z, Queen K, Tao Y, Eltahir Y, et al. Zoonoticorigin and transmission of Middle East respiratory syndrome coronavirus in the UAE. Zoonoses Public Health 2018;65 (3):322-33.

9. Raj VS, Mou H, Smits SL, Dekkers DH, Müller MA, Dijkman R, et al. Dipeptidylpeptidase 4 is a functional receptor for the emerging human coronavirus-EMC. Nature 2013;495 (7440):251-4.

10. Bertram S, Glowacka I, Müller MA, Lavender H, Gnirss K, Nehlmeier I, et al.Cleavage and activation of the severe acute respiratory syndrome coronavirus spike protein by human airway trypsin-like protease. J Virol 2011;85 (24):13363-72.

11. Wu A, Peng Y, Huang B, Ding X, Wang $X$, Niu $P$, et al. Genome composition anddivergence of the novel coronavirus (2019-nCoV) originating in China. Cell Host Microbe 2020.

12. Xu X, Chen P, Wang J, Feng J, Zhou H, Li $\mathrm{X}$, et al. Evolution of the novelcoronavirus from the ongoing Wuhan outbreak and modeling of its spike protein for risk of human transmission. Sci China Life Sci 2020;1-4.

13. Geo-Vax. Geovax and bravovax (wuhan, china) to collaborate on development of coronavirus vaccine. [cited $20203 \mathrm{March}$ ];
Available

from:

https://www.geovax.com/news/geovax-

and-bravovax-wuhan-china-to-collaborateondevelopment-of-coronavirus-vaccine.

14. World Health Organization. Laboratory testing of human suspectedcases of novel coronavirus (nCoV) infection [published online aheadof print January 21, 2020]. https://apps.who.int/iris/bitstream/handle/1 0665/330374/WHO- 2019- nCoV- labora tory- 2020.1- eng.pdf

15. World Health Organization. Novel Coronavirus (2019- nCoV) situation report- 2 [published online ahead of print January 21, 2020]. https://www.who.int/docs/default- source/ coronaviruse/situation- reports/20200122 - sitrep- 2- 2019- ncov.pdf

16. World Health Organization. Middle East respiratory syndrome coronavirus (MERS- CoV) [published online ahead of print January 21,2020]. https://www.who.int/emergencies/mers- c ov/en/

17. World Health Organization. WHO MERS global summary and assessment of risk [published online ahead of print January 21 , 2020]. https://www.who.int/csr/disease/coronavir us_infections/risk- assessment- august- 2 018.pdf?ua $=1$

18. Yoneyama M, Fujita T. RNA recognition and signal transduction by RIG- I- like receptors. Immunol Rev. 2009;227 (1):54- 65 .

19. Strasser D, Neumann K, Bergmann H, et al. Syk kinase- coupled C-typelectin receptors engage protein kinase $\mathrm{C}$ - sigma to elicit Card9 adaptormediated innate immunity. Immunity. 2012;36(1):32- 42.

20. Li Q, Guan X, Wu P, et al. Early transmission dynamics in Wuhan,China, of novel coronavirus-infected pneumonia. $\mathrm{N}$ Engl J Med 2020. https://doi.org/10.1056/NEJMoa2001316. 
21. Chen N, Zhou M, Dong X, et al. Epidemiological and clinical characteristics of 99 cases of 2019 novel coronavirus pneumonia in Wuhan, China: a descriptive study. Lancet. 2020;395:50713.

22. Xu XW, Wu XX, Jiang XG, et al. Clinical findings in a group ofpatients infected with the 2019 novel coronavirus (SARS-Cov-2) outside of Wuhan, China: retrospective case series. BMJ. 2020;368:m606.

23. Russell CD, Millar JE, Baillie JK. Clinical evidence does not support corticosteroid treatment for 2019-nCoV lung injury. Lancet. 2020;395:473-5.

24. World Health Organization. Coronavirus disease [COVID-19]Technical Guidance: Infection Prevention and Control. Available at: https://www.who.int/emergencies/diseases /novel-coronavirus-2019/technicalguidance/infection-prevention-and-control. Accessed 20 Feb 2020.

25. H. Lu, C.W. Stratton, Y.W. Tang, Outbreak of pneumonia of unknown etiology inwuhan China: the mystery and the miracle, J. Med. Virol. 92 (4) (2020) 401-402, https://doi.org/10.1002/jmv.25678.

26. J. Lei, J. Li, X. Li, X. Qi, CT imaging of the 2019 novel coronavirus (2019-nCoV) pneumonia, Radiology (2020) 200236, https://doi.org/10.1148/radiol.2020200236.

27. A. Assiri, J.A. Al-Tawfiq, A.A. AlRabeeah, F.A. Al-Rabiah, S. Al-Hajjar, A. Al-Barrak, et al., Epidemiological, demographic, and clinical characteristics of 47 cases of Middle East respiratory syndrome coronavirus disease from Saudi Arabia: a descriptive study, Lancet Infect. Dis. 13 (2013) 752-761.

28. W. Ji, W. Wang, X. Zhao, J. Zai, X. Li, Homologous recombination within the spike glycoprotein of the newly identified coronavirus may boost cross-species transmission from snake to human, J. Med.

Virol. 92 (4) (2020) 433-440, https://doi.org/10.1002/jmv.25682.

29. Y. Wan, J. Shang, R. Graham, R.S. Baric, F. Li, Receptor recognition by novel coronavirus from Wuhan: an analysis based on decade-long structural studies of SARS, J. Virol. (2020), https://doi.org/10.1128/JVI.00127-20.

30. D.S. Hui, E. IA, T.A. Madani, F. Ntoumi, R. Kock, O. Dar, et al., The continuing 2019-nCoV epidemic threat of novel coronaviruses to global health - the latest 2019 novel coronavirus outbreak in Wuhan, China, Int. J. Infect. Dis. 91 (2020) 264-266.

31. M. Wang, R. Cao, L. Zhang, X. Yang, J. Liu, M. Xu, et al., Remdesivir and Chloroquine Effectively Inhibit the Recently Emerged Novel Coronavirus (2019nCoV) in Vitro, Cell research, 2020.

32. M. Toots, J.J. Yoon, R.M. Cox, M. Hart, Z.M. Sticher, N. Makhsous, et al., Characterization of orally efficacious influenza drug with high resistance barrier in ferrets and human airway epithelia, Sci. Transl. Med. (2019) 11.

33. Y.H. Jin, L. Cai, Z.S. Cheng, H. Cheng, T. Deng, Y.P. Fan, et al., A rapid adviceguideline for the diagnosis and treatment of 2019 novel coronavirus (2019-nCoV) infected pneumonia (standard version), Mil. Med. Res. 7 (2020) 4.1

34. J.A. Jaimes, J.K. Millet, A.E. Stout, N.M. Andre, G.R. Whittaker, A tale of two viruses: the distinct spike glycoproteins of feline coronaviruses, Viruses 12 (2020).

35. D.S. Hui, E. IA, T.A. Madani, F. Ntoumi, R. Kock, O. Dar, et al., The continuing $2019 \mathrm{nCoV}$ epidemic threat of novel coronaviruses to global health - the latest 2019 novel coronavirus outbreak in Wuhan, China, Int. J. Infect. Dis. 91 (2020) 264-266. 
36. J. Cui, F. Li, Z.L. Shi, Origin and evolution of pathogenic coronaviruses, Nat. Rev. Microbiol. 17 (2019) 181-192.

37. N. Chen, M. Zhou, X. Dong, J. Qu, F. Gong, Y. Han, et al., Epidemiological and clinical characteristics of 99 cases of 2019 novel coronavirus pneumonia in Wuhan, China: a descriptive study, Lancet 395 (10223) (2020) 507-513, https://doi.org/10.1016/S01406736(20)302 11-7.

38. J. Cui, F. Li, Z.L. Shi, Origin and evolution of pathogenic coronaviruses, Nat. Rev. Microbiol. 17 (2019) 181-192.

39. Chan JF-W, Kok K-H, Zhu Z, Chu H, To KK-W, Yuan S, et al. Genomic characterization of the 2019 novel humanpathogenic coronavirus isolated from a patient with atypical pneumonia after visiting. Wuhan. Emerging Microbes \& Infections 2020;9(1):221-36.

40. Raj VS, Mou H, Smits SL, Dekkers DH, Müller MA, Dijkman $R$, et al. Dipeptidylpeptidase 4 is a functional receptor for the emerging human coronavirus-EMC. Nature 2013; 495(7440):251-4. 